\title{
Information transmission efficiency in neuronal communication systems
}

\author{
Bartosz Paprocki ${ }^{1}$, Janusz Szczepanski ${ }^{1,2}$, Dorota Kolbuk ${ }^{2^{*}}$ \\ From Twenty Second Annual Computational Neuroscience Meeting: CNS*2013 \\ Paris, France. 13-18 July 2013
}

The nature and efficiency of brain transmission processes, its high reliability and efficiency is one of the most elusive area of contemporary science [1]. We study information transmission efficiency by considering a neuronal communication as a Shannon-type channel. Thus, using high quality entropy estimators, we evaluate the mutual information between input and output signals. We assume model of neuron proposed by Levy and Baxter [2], which incorporates all essential qualitative mechanisms participating in neural transmission process. We analyze how the synaptic failure, activation threshold and characteristics of the input source affect the efficiency. Two types of network architectures are considered. We start by a single-layer feedforward network and next we study brain-like networks which contains components such as excitatory and inhibitory neurons or long-range connections. It turned out that, especially for lower activation thresholds, significant synaptic noise can lead even to twofold [Figure 1] increase of the transmission efficiency [3]. Moreover, the more amplifying the amplitude fluctuation is, the more positive is the role of synaptic noise [4]. Our research also shows that all brain-like network components, in broad range of conditions, significantly improve the information-energetic efficiency. It turned out that inhibitory neurons can improve the information-energetic transmission efficiency by 50 percent, while long-range connections can improve the efficiency even by 70 percent. The knowledge of the effects of the long-range connections could be particulary useful when we consider possible reconstruction or support of them applying biomaterials $[5,6]$. We also showed that the most effective is the network with the smallest size: we found that two times increase of the size can cause even three times decrease of the information-energetic efficiency [7].

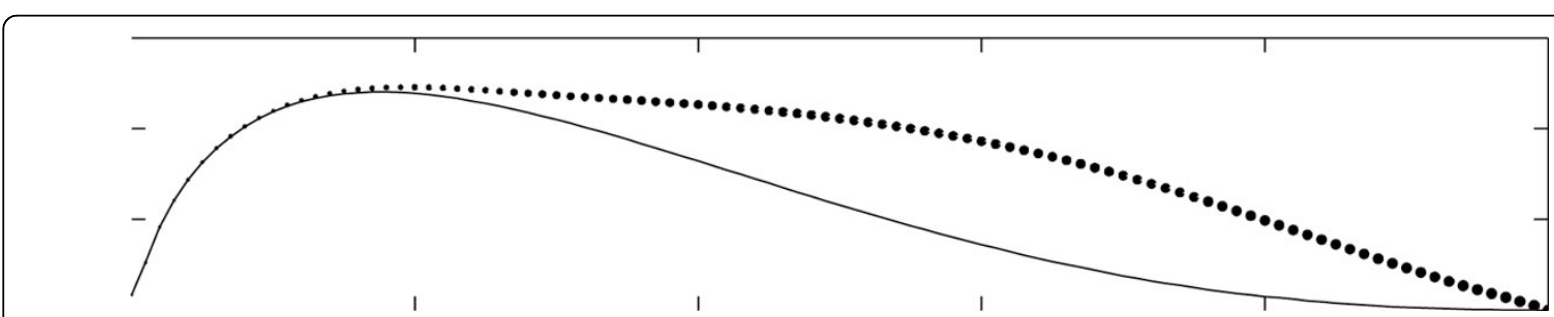

Figure 1 Mutual information dependency on synaptic success, $s$, in single-layer neural network. Maximal mutual information values (dotted line) and these achieved at $s=1$ (solid). Size of a given dot is proportional to 1-s, indicating the bigger the dot, the corresponding mutual information value is achieved at lower $s$ [3].

\footnotetext{
${ }^{2}$ Institute of Fundamental Technological Research, Polish Academy of

Sciences, Warsaw, Poland

Full list of author information is available at the end of the article
}

(c) 2013 Paprocki et al; licensee BioMed Central Ltd. This is an Open Access article distributed under the terms of the Creative 


\section{Acknowledgements}

This paper has been supported by Polish National Science Centre Grant N N519 646540 .

\section{Author details}

${ }^{1}$ Institute of Mechanics and Applied Computer Sciences, Kazimierz Wielki University, Bydgoszcz, Poland. ${ }^{2}$ Institute of Fundamental Technological Research, Polish Academy of Sciences, Warsaw, Poland.

Published: 8 July 2013

\section{References}

1. van Hemmen JL, Sejnowski T: 23 problems in Systems Neurosciences. Oxford University 2006.

2. Levy W, Baxter R: Energy-efficient neuronal computation via quantal synaptic failures. Journal of Neuroscience 2002, 22:4746-4755.

3. Paprocki B, Szczepanski J: Efficiency of neural transmission as a function of synaptic noise, threshold, and source characteristics. Biosystems 2011, 105:62-72.

4. Paprocki B, Szczepanski J: How do the amplitude fluctuations affect the neuronal transmission efficiency. Neurocomputing 2013, 104:50-56.

5. Kołbuk D, Sajkiewicz P, Kowalewski TA: Optical birefringence and molecular orientation of electrospun polycaprolactone fibers by polarizing-interference microscopy. European Polymer Journal 2012, 48:275-283.

6. Hu A, Zuo B, Zhang F, Lan Q, Zhang H: Electrospun silk fibroin nanofibers promote Schwann cell adhesion, growth and proliferation. Neural Regeneration Research 2012, 7(15):1171-1178.

7. Paprocki B, Szczepanski J: Transmission efficiency in the brain-like neuronal networks. Information and energetic aspects. Neural Coding Workshop 2012, Prague.

doi:10.1186/1471-2202-14-S1-P217

Cite this article as: Paprocki et al:: Information transmission efficiency in neuronal communication systems. BMC Neuroscience 2013 14(Suppl 1): P217.

\section{Submit your next manuscript to BioMed Central} and take full advantage of:

- Convenient online submission

- Thorough peer review

- No space constraints or color figure charges

- Immediate publication on acceptance

- Inclusion in PubMed, CAS, Scopus and Google Scholar

- Research which is freely available for redistribution

Submit your manuscript at www.biomedcentral.com/submit
Biomed Central 